\title{
Psicodrama e inclusión social. La línea tenue de la marginación.
}

\author{
Claudia PAZ ROMÁN ${ }^{1}$ \\ davidlabestia@hotmail.com
}

Enviado: $19 / 05 / 11$

Aceptado: 12/10/2011

\begin{abstract}
RESUMEN
Este artículo es una reflexión en torno a la condición de marginalidad en la cotidianeidad plasmándose en la expulsión de los lugares placenteros en la gran urbe (ciudad de México) y su transitar bajo la incertidumbre; el temor y el sufrimiento. Por ello se intenta rescatar el sentido del grupo a partir de estrategias psicodramáticas como el refugio creador que permitan sobrevivir a través del encuentro y empoderamiento del "no lugar".
\end{abstract}

Palabras clave: marginalidad, exclusión, abyección, psicodrama y refugio.

\section{Referencia normalizada}

ROMÁN, C. P. (2011). "Psicodrama e inclusión social. La línea tenue de la marginación.”. En Arteterapia: Papeles de arteterapia y educación artística para la inclusión social Vol.: 6. Páginas 195-208. Madrid. Servicios de publicaciones UCM.

\section{SUMARIO:}

Psicodrama, arte e inclusión social. Marginación. La marginación cotidiana, un espacio de invisibilidad. Abyección. Formas de simulación psicosocial. Exclusión. Violencia en México. Marginalidad y violencia. Sobrevivencia. Espacios de refugio. La mirada escénica psicodramática ante la indiferencia. Conclusiones. Referencias bibliográficas.

\section{Psychodrama and social incorporation. The tenuous line of the marginalization}

\begin{abstract}
This article is a reflection about marginalization in every day life, materialized in the expulsion of pleasurable places of the metropolis (Mexico City), and in its journey through uncertainty, fear and suffering. For this reason we try to rescue the meaning of the group through strategies of psychodrama. We think of it as a creative refuge that allows survival because it promotes the discovery and empowerment of that "no place".
\end{abstract}

Keywords: marginalization, being apart, abjectness, psychodrama and refuge.

${ }^{1}$ Profesora-Investigadora de la Universidad Autónoma Metropolitana. Unidad. Xochimilco. México. División de Ciencias Sociales y Humanidades. Departamento de Educación y Comunicación. Profesora-investigadora 


\title{
CONTENTS:
}

Psychodrama art and social inclusion. Marginalization. Marginalization in every day life, a space of invisibility. Abjection. Forms of psycosocial simulation. Exclusion. Violence in Mexico. Marginality and violence. Survival. Spaces of refuge. The scenic look psicodramatica before the nonchalance. Conclusions. Bibliography.

\author{
Dejaré de ser hermoso. \\ Pronto, mi rostro revelará mis vicios: envejeceré. \\ Con esta idea puedo sentirme humillado \& vencidopero, sobre todo, sé que debí haber com- \\ prado, vendido, después, y haber ganado/tenido/gastado pero sido. \\ E. Oláiz (Hermandad, inédito).
}

\section{PSICODRAMA, ARTE E INCLUSIÓN SOCIAL}

El psicodrama es la conjunción entre arte, psicología y filosofía y, su pertinencia en el campo de la psicología social ha sido sorprendente. En palabras del creador del psicodrama, Jacob Levy Moreno: el Psicodrama nace por y para el grupo; es un método para explorar a fondo la verdad del alma a través de la acción. Históricamente el psicodrama representa el punto decisivo en el pasaje del tratamiento del individuo aislado hacia el tratamiento grupos; del tratamiento del individuo con métodos verbales hacia el de métodos de acción.

Las adversidades con las que el hombre se enfrenta y se confronta son el origen de esta metodología. Definiendo "psicodrama" como psique en acción, posibilidad de un despliegue espontáneo y creativo frente a las situaciones adversas de índole psicosocial, podría decirse que el tema de la inclusión social atraviesa permanentemente el campo psicodramático.

Regresar al origen, a aquello que miró Moreno y que lo inspiró a la conformación de su teoría, es fundamental en el rescate de su pensamiento y filosofía. Al psicodrama se le ha conocido como una técnica más de intervención grupal, y se le ha reducido a tal consideración. Sin embargo, la propuesta psicodramática es una propuesta teórico-metodológica que enmarca la acción; el "aquí" y el "ahora" son los fundamentos básicos de la dramatización y, entender qué es el psicodrama no es, simplemente, conocer sus técnicas, sino adentrarse a comprender los fundamentos histórico-filosóficos que lo conforman. Las ideas morenianas están influenciadas por el existencialismo; aunque, para él, los verdaderos existencialistas realizan una existencia profética in actu in situ, poniendo en práctica la experiencia existencial a tal grado que "existencia" y "conocimiento" sean una sola cosa.

Moreno plantea, así, la filosofía del momento, el momento de crear, que es un instante grandioso, y es único. En la dramatización se aparecen presente, pasado y futuro confluyendo en un preciso momento: el de la representación; momento privilegiado, de expresión espontánea y creativa. La representación en psicodrama, tiene significación y sentido propios, no reduzcamos el psicodrama a una mera representación, sin tener bien clara la significación de la misma o a cuál teoría hacemos referencia. 


\section{MARGINACIÓN Y EXCLUSIÓN}

El tema del presente artículo es la tragedia de la marginación, en cuanto a inclusión social se refiere. La construcción de un drama en la tragedia, se hace posible a través de la intervención psicodramática. Una de las grandes virtudes del psicodrama es la transformación escénica en la vivencia interna del protagonista, pues es él quien tiene que hacerse cargo de la obra, teniendo, entonces, el derecho de escribir o modificar el guión de la misma. A veces podemos elegir nuestros escenarios pero, en otras, aparecemos en ellos, transitamos por poco o mucho tiempo y, también a través de la imaginación, nos trasladamos a otros. En fin, simplemente somos sujetos actores, siempre dentro de un escenario, y el dispositivo psicodramático es un facilitador para vislumbrar cómo vivenciamos y ejecutamos cada uno nuestra obra en los diversos escenarios, y los personajes significativos que exteriorizamos durante la dramatización. En palabras de Michel Foucault, el dispositivo es lo que permite separar, no lo verdadero de lo falso, sino lo incalificable científicamente respecto de lo calificable.

Representar es, hacer presente lo imaginable, ser protagonista de la propia existencia y compartirla con la audiencia, quienes acogen o desaprueban nuestra obra dramática.

Investigar a través de un dispositivo psicodramático permite mirar, hablar desde el lenguaje de la acción y, es en la acción de condiciones de dificultad donde Moreno conformó su teoría , miró lo no mirado en las escenas cotidianas, consideró digno de atención un suceso colectivo de la vida real, el escenario de la dificultad, donde el ser, que es actor, requiere de la acción, de dar una respuesta inmediata y, por las condiciones mismas de la situación, es un tiempo presente, concentrado con toda su percepción y facultades para actuar y dar respuestas nuevas frente a lo inesperado o lo diferente, frente a un escenario desconocido.

Pareciera ser que la existencia del ser humano transcurre bajo una neblina gris, con una corta percepción y la anulación de las capacidades sorpresiva y expresiva. Es por ello que en el psicodrama se trabaja el cambio de lugar en escena; a través de una serie de técnicas, este cambio de lugar permite una mirada diferente, así como la sorpresiva posibilidad de un accionar nuevo. En condiciones de crisis los escenarios cambian: lugares otrora nuestros ya no lo son más, la percepción y el sentido cobran otra dimensión, nos hacemos preguntas que en otras circunstancias ni se nos ocurrirían, nos relacionamos de maneras diferentes, en función a una ruptura cotidiana.

Comenzaré, como todos los psicodramatistas lo harían, a partir de algunas narraciones de escenas de marginación y exclusión, la tragedia de la marginalidad, con el fin de analizar aquello que fue trazando la línea tenue de la marginación. 


\section{LA MARGINACIÓN COTIDIANA, UN ESPACIO DE INVISIBILIDAD}

La experiencia es a partir de la gripe $A$ (H1N1); verdad o mentira, aún no lo sabemos. Algo extraño invadió el ambiente, primero en México, y después a nivel mundial, desapareciendo de una manera "bastante extraña". Mi intención no es hablar de la gripe y mi extrañeza, sino del lugar en el que, súbitamente, mi hija y yo, fuimos colocadas mientras participábamos en el último Congreso Iberoamericano de Psicodrama en Ecuador. Yo tuve la fortuna de entrar al país, algunos compañeros mexicanos no; ellos fueron expulsados, mientras mi hija y yo fuimos separadas del resto de los turistas, en ese lugar, que representa lo inhóspito, el lugar de la expulsión, el lugar de lo incierto y de la espera tortuosa: El lugar de la no pertenencia. Mi trabajo profesional, se ha enfocado en la población marginada (presas, inmigrantes, indígenas, etcétera), sin embargo, durante esta experiencia estaba colocada del otro lado, en una especie de trampa social, una inversión de rol abrupta y sin consideración alguna. Súbitamente, ya estaba del otro lado: tenía la forma y condición del abyecto.

\section{ABYECCIÓN}

Recordé el artículo de un colega universitario, el Dr. Roberto Manero, con relación a la abyección y que dice lo siguiente:

$A b$, prefijo que denota separación, algo que se deja de lado, algo que se intensifica [...] Jectum, verbo que significa lanzar, aventar, arrojar. Separar y arrojar, así nace lo abyecto. El conocimiento del mundo, la lógica conjutista-identitaria en términos castoridianos, supone el abjecto, la taxonomía y sus consecuencias: sagrado-profano, puro-impuro, limpio-sucio, buenomalo. Separamos lo que se encuentra unido. Y aventamos (jectum) una parte, eso separado, lo malo, lo sucio [...] lo sagrado. La abyección es un sinónimo de la humillación. Y la humillación, en tanto abyección, está muy presente en todos lados.

Lo que más me sorprendía era cómo me miraban los demás, (extranjeros para mí, y nosotras para ellos). Podía dar lectura a sus pensamientos. Al parecer, nuestra simple presencia les atemorizaba y amedrentaba, por tanto, deseaban expulsarnos del grupo. Entre esa espera incierta, durante la que ya no me pertenecía, experimenté momentos de angustia por no saber lo que nos ocurriría, pero si lo demostraba sería peor: ¡Pensarían que estoy infectada! Así que, una sonrisa irónica surgía inesperadamente. Y después, comencé a pensar en las estrategias para librarme de esa situación, recordé mis aportaciones psicodramáticas (las que atañían a las estrategias de sobrevivencia en la prisión) y me moví del sitio en una necesaria trasgresión que implicaba aventurarse, ya fuera a la expulsión total o a la inclusión. Mi campo de observación era amplio, al parecer en ese sentido ocupaba un lugar privilegiado y, por tanto, podía saber el momento oportuno de irrumpir y dar una explicación 
contundente, que nos permitiera, a mí y a mi hija, poder librarnos de ese sitio tremendamente injusto e incómodo que ocupábamos. Lo único que deseaba, en ese momento, era ya no ocupar más ese frío e incómodo lugar. Así, los minutos se me hacían eternos, recordaba lo que las reclusas me decían sobre el transcurrir del tiempo en el hacinamiento (he realizado varias intervenciones psicodramáticas en la prisión). Miraba cómo todos pasaban y nosotras permanecíamos en el mismo sitio, hasta que funcionó mi argumento contundente y nos liberaron, lo cual agradecí profundamente, con una extraña sensación, como si me hubiesen hecho algún favor. Por supuesto, lo de mexicana nadie me lo quitaba y eso era asociado a la enfermedad, al contagio y a la posible muerte. Una absoluta carencia de racionalidad, marcaba el traspaso de la línea tenue de la marginación. La línea permanecía tenue pero, al parecer, imborrable y, aunque nos permitieron transitar como los otros, nunca desapareció durante el viaje (una vez que se es marcado, es difícil borrar la marca: la condición del estigmatizado nos invadía el ser).

\section{FORMAS DE SIMULACIÓN PSICOSOCIAL}

Esta es la línea tenue que subrayo en este escrito. Todos estamos en riesgo de cruzarla sin percatarnos de ello. Su imperceptibilidad es, gracias a las múltiples formas de simulación psicosocial. Por ejemplo, cuando escuchamos que todos somos iguales, que no hay problema. Esa línea se desplaza con nosotros en el día a día. Hasta que sorpresiva y repentinamente toma color, forma y significado, como en el caso narrado, y no sabemos qué responder, qué estrategias utilizar. En cualquier momento, podemos estar "del otro lado"; tal como los inmigrantes mexicanos lo expresan: basta cruzar la línea y es la salvación o la condena. La marginación es, entonces, un acto de violencia.

Qué más violencia que ser desempoderado de tu ser, de que tus deseos sean echados por la borda, de no ser tratado como igual. El pánico colectivo produce formas violentas. El discurso mundial nos convierte en seres marginados en cualquier instante: desde ser un posible terrorista y estar vigilado bajo una violencia disfrazada, en el aeropuerto; hasta, en el momento de solicitar una visa para ingresar a otro país y ser tratado de manera poco amable y poniendo en duda todo lo que se pueda decir. De nuevo, sentir que se debe agradecer porque se carece del derecho a ser tratado bien y se está haciendo un favor al dar una visa y pasar "migración"; al ser robado y no asesinado en la gran urbe, etcétera, etcétera... Pedir perdón, en mi país, es una costumbre cotidiana. Disculparse de todo, bajo el autoritarismo impuesto en la ideología y en la ausencia de cobijo del Estado. ¿A quién recurrir cuando somos maltratados al habitar un "otro lugar", el de la no-pertenencia, de una manera impertinente al parecer de otros?

Es en el ínter, en el pasaje de un lado a otro, en el cual los actos de marginación y violencia cobran mayores proporciones. Es en el "no lugar" en donde el abuso de poder "hace de las suyas". Algunas de las dramatizaciones significativas plasmadas en los grupos marginados, han sido durante el tránsito de un país a otro, mientras se es habitante extranjero, extraño y por tanto vulnerable y posible depositario de los 
miedos y odios más recónditos. Sin embargo, quisiera hacer énfasis, en esta ocasión, en la marginación cotidiana, en la que habitamos en el "día a día" y que, al parecer, es algo "normal" (lo que la cotidianeidad coloca en una supuesta normalidad). Así, lo cotidiano eclipsa las posibles reflexiones al respecto, haciendo por demás difícil percatarse de las múltiples circunstancias con las que la marginación cotidiana invade y recrea nuestro espacio vital.

\section{EXCLUSIÓN}

Por ello, el presente trabajo da una vuelta de tuerca, al considerar a la marginación desde lo cotidiano. Esa, la que oculta e imposibilita la mirada, me atrevería a decir que también impide trabajar contra la problemática de la inclusión social, no existiendo, así, la posibilidad de colocarnos en circunstancias propias de exclusión, que sensibilicen a los profesionistas dedicados a este campo, lo que en psicodrama equivaldría no solo a la inversión de rol, sino a la identificación del rol de exclusión en el recuerdo significativo del profesionista.

La conformación del lugar marginado, en este caso en particular, en México, a partir de las formas de violencia generadas por el Estado, por ejemplo, una guerra contra el narcotráfico que invade el espacio y la condición del supuesto "no marginado"; del que habita el lugar de la no pertenencia, del despojo y del olvido. Se vive como marginado aunque no se nombre como tal, pero hay similitudes y grandes aportaciones que aquellos, los considerados marginados (llámense presas, inmigrantes e indígenas), aportan a este trabajo en el campo de la experiencia y las estrategias de sobrevivencia. Este trabajo rescata las experiencias de sobrevivencia que los grupos marginados (en especial las mujeres en prisión) aportan para que, aquellos que no están tras las rejas puedan sistematizarlas contra la condición de encierro real, imaginario o simbólico en el que transitamos permanentemente.

Curiosamente, en los grupos psicodramáticos en que se trabajó con población "no marginada", todos habían tenido alguna experiencia de robo, asalto o maltrato en la ciudad, todos lo habían vivido en más de una ocasión: Ser sometidos y violentados, condición fundamental de estos tiempos de marginación cotidiana. Al dramatizar las escenas pudieron mirar su vulnerabilidad, y que éstas podrían volver a suceder en cualquier momento, repetir la incertidumbre, como factor principal del estado del marginado. Ahora se había aprendido y ya no se era "marginado principiante" (por decirlo de alguna manera), se intentaba tener más cuidado, porque se asumía el peligro y la condición en su clara y cruda realidad: La conciencia del espacio en el que se habita. 


\section{VIOLENCIA EN MÉXICO}

Los actos de violencia en México, que narran desde sucesos en la cotidianeidad del supuesto no marginado hasta la autorización para dar muerte al marginado (desde la violencia en la frontera México-E.E.U.U. hasta la guerra contra el narcotráfico), se viven en una cotidianeidad aceptable y clandestina. Se parte del supuesto de que no se puede explicar la marginación sin referirse a la violencia. La violencia como acto es la abyección, significación de la separación y de la expulsión.

En el "día a día" y en una gran urbe, como en la Ciudad de México, se es permanentemente expulsado; en una ceguera de colocación, en múltiples ocasiones, por no considerarse marginado (pobre, inmigrante, indígena, ese otro que no soy yo). La estigmatización del rol del marginado, no facilita el hecho de tener otras miradas en cuanto a los roles frente a la marginación. Entonces él (el ¿no marginado?) no mira su real y cotidiana expulsión de su territorio, en el que se vive cada vez más como extranjero, extraño ante su propio país; sensación de extrañeza sobre sus convicciones y cultura. Porque cada vez las ejerce con menor frecuencia. Ha sido desempoderado por una constante gota que cae en el transcurrir del tiempo y, entonces, se ha olvidado de quién es, cuáles son sus deseos, sus preferencias, sus ideales.

El tiempo y el espacio ya no le pertenecen, por tanto, su ser transita en la inercia cotidiana en formas de vida con premura, vertiginosidad que propicia la escasez de pausas reflexivas frente al acontecer cotidiano y mundial. Desde aquí se traza la línea tenue de la marginación. Entonces, cómo trabajar con marginados, si no reconocemos nuestra propia marginación, si no focalizamos las circunstancias en las que hemos vivido total y absolutamente marginados. La línea es tan tenue, que trastoca lo burdo y lo grotesco; y la negación a mirarlo y, peor aún, cruzar la línea sin saberlo. El ambiente frente a la globalización torna infantil a la percepción, experimentando la extrañeza, pero no como la del niño, que es curioso, sino como un adulto sin creencia ni esperanza. La reflexión sobre el tema de la marginación en sus burdas y múltiples formas que surgen en esta gran y maravillosa urbe como lo es la ciudad de México, posibilite, tal vez, una pequeña dosis de sensibilidad y conciencia.

Este trabajo está conformado por documentación periodística y estudio de campo principalmente (con metodología psicodramática).

Todos hemos vivido alguna experiencia de marginación, ya fuera de pequeños, en la escuela o, de adolescentes, al no pertenecer a alguno de los grupos deseados; o en la familia. Nadie se escapa de la marginación y de sus consecuencias, en ocasiones, devastadoras, psíquica y físicamente. Sin embargo, éstas son circunstancias de marginación pasajeras, la peligrosa es la permanente, aquélla, la marginación que se diluye, la que no lo parece porque se esconde bajo discursos enredosos de poder, justicia y nacionalismo. La marginación del día a día. La marginación que nos lleva a no desear salir a la calle a divertirse; la que nos impide poder ir al parque y disfrutar; la que se empodera de nuestro tiempo en largas filas en el banco; o en el tránsito cotidiano; la que nos impide enriquecer los vínculos familiares; la que propicia tra- 
bajar más de ocho horas y no tener tiempo sólo para lo absolutamente necesario. La marginación de las grandes urbes, inserta en un discurso de mercadotecnia que nos lleva a espacios de consumo, a habitar lugares nice y suponer que eso es lo valioso.

\section{MARGINALIDAD Y VIOLENCIA}

La marginación que orilla a la degradación del ser humano, porque restringe nuestros deseos, nuestra calidad de vida, y conlleva a una existencia en un sinsentido, por su condición de no-pertenencia. Esa es la marginación de la que quiero reflexionar en estas breves líneas, no como extranjero ni extraño, sino como un ser humano que lucha día a día por tener espacios de desarrollo profesional y anímico. Escribir es, en ocasiones, intentar dar voz a un colectivo que pide a gritos reflexionar sobre las actuales condiciones en las que las grandes urbes cohabitan o, viéndolo más allá, en los "valores globalizados" porque, así como todos, hemos vivido alguna circunstancia pasajera de marginación. Posiblemente, al enfermar o envejecer, la situación no será ya pasajera, e intentaremos ocupar lugares en los que ya no habrá cabida y, entonces, andaremos deambulando como perdidos, intentando hacer plática cuando uno compra el periódico o un pedazo de pan. La marginación en sus últimas consecuencias significa vivir en soledad, abandono e indiferencia, en donde la violencia se plasma en su forma cruel y cruda. Entonces recordaremos a esos niños que miramos limpiando el parabrisas en las esquinas; o a esos indígenas maltratados; a esos inmigrantes sobajados; a esos adictos incomprendidos; a los esquizofrénicos, obligados a habitar sólo el espacio de sus mentes; y nos percataremos que ahora también habitamos su mundo: el de la exclusión y la indiferencia.

En un artículo sobre Marginalidad y violencia, publicado el viernes 25 de junio del 2010, en el periódico La Jornada de la Ciudad de México, José Cuelli, escribe lo siguiente:

Entre los marginados la principal preocupación es la sobrevivencia día con día, la muerte es una realidad que se hace presente a cada momento, ya sea por enfermedad o por violencia cotidiana que se incrementa de manera escabrosa a lo largo y ancho de todo el país [...] Mientras tanto pensemos en los millones de mexicanos que viven, mejor dicho sobreviven a dramáticas circunstancias ahogándose (o muriendo) entre la miseria, el analfabetismo, el terror y la violencia extrema debido a una cruel, despiadada y perversa desigualdad social [...] Víctimas de la incontenible ola de violencia y criminalidad.

Entonces no estamos tan lejos de ser marginados, y debemos crear conciencia de tal condición. Entre las consideradas poblaciones marginadas y los supuestos marginados, ya no hay grandes diferencias, existe solo una línea muy tenue. La guerra contra el narcotráfico, en mi país, nos coloca ya en esta línea, en la frontera, nos convierte en el ciudadano que el gobierno margina, que está a su merced. 
Una de las características de la marginalidad, es el sufrimiento extremo.

Cuelli, en el artículo periodístico titulado Angustia ante la inseguridad extrema y la violencia, comenta:

En la dramática circunstancia en que vivimos desde hace ya mucho tiempo los mexicanos, debido a la inseguridad extrema, a la violencia y al abuso sin límite, nos han colocado en una situación traumática permanente donde los protagonistas principales son la angustia, el dolor y los duelos no elaborados [...] Sobre un trauma se suma otro más. El yo se ve desbordado, sin posibilidades de elaboración de la situación traumática. El dolor y la rabia nos rebasan. Existe un peligro real.

Acaso, ¿aún hay duda de la condición de marginación en la que vivimos día con día? Bajo esta condición, ¿seremos sobrevivientes? El marginado se convierte en un sobreviviente.

\section{SOBREVIVENCIA}

Mucho aprendizaje me ha dejado el trabajo psicodramático con grupos "vulnerables", grupos marginados, sobretodo en cuanto a las diversas estrategias que se desarrollan para sobrevivir, porque el marginado permanentemente está en un estado de sobrevivencia.

En el diccionario se define sobrevivir como: vivir uno más que otro, después de la muerte de otro o después de un determinado suceso o plazo. Entonces, en el sobreviviente hay un plus, por llamarlo de alguna manera, ese "algo más" que obliga al ser humano a sortear condiciones que llevarían a la muerte; el ser humano es capaz de sortearlas, en parte gracias a su inteligencia y, en otra, por el deseo de vivir y la esperanza de salir de esas circunstancias. Esperanza, orgullo, deseo, imaginación, inteligencia y desarrollo de estrategias son fundamentales en el asunto de sobrevivir. Pensar que, sea la circunstancia que sea, va a pasar, que esa forma de vida no es eterna; desarrollar, a partir de ello, estrategias cotidianas que le permitan permanecer en esos acontecimientos insospechados como un gran estratega: Sí, el sobreviviente echa mano de su inteligencia y creatividad para poder vivir.

Existe una palabra similar que es sobrevienta, golpe de viento impetuoso. Furia, ímpetu. Sobresalto, sorpresa. De repente improvisa, impensadamente. El sobreviviente tiene la característica de aguantar el golpe, la furia que se descarga y que pretende, a toda costa, aniquilarlo. Se le toma por sorpresa, con una forma de aniquilamiento paulatino. Mutilar al sujeto, tomarlo por sorpresa, la irrupción e interrupción, la vigilancia permanente y la violencia constante, esta violencia se vierte en las formas cotidianas.

En la sobrevivencia persiste lo clandestino, esconderse para no decir qué se hizo o qué se hace para sobrevivir. Una vez salidos de esa situación, también sale a la luz 
la diversidad de formas que para ello existen. Un preso me decía: Lo importante es lograr el objetivo, que no te maten.

Infinidad de historias que han sido, incluso, inspiración para guiones cinematográficos, que muestran la capacidad y la grandeza del ser humano en condiciones inhóspitas. El ser humano es capaz de sobrevivir en las circunstancias más adversas. Se vive en esta "otra realidad". Pero, ¿cómo se vive bajo el estigma de la marginación? ¿Qué significado tiene esa nueva realidad? ¿Cómo es posible la adaptación y qué mecanismos internos se desarrollan para poder adaptarse? Varias son las preguntas, y las respuestas a partir de considerarnos sobrevivientes en las actuales condiciones en que vive México y, posiblemente, otras partes del mundo. Somos actuales sobrevivientes de la furia de la naturaleza y de la furia de las autoridades que gobiernan. Furia incontrolable que los sobrevivientes y marginados soportan bajo sus espaldas, carga cotidiana, sucesos incontrolables que propician la expulsión en sus diversas circunstancias y condiciones.

Por ello, las estrategias de sobrevivencia que los grupos marginados han compartido, y me han mostrado en el escenario psicodramático, podrían ser un parámetro necesario para los estados de marginación cotidiana y cómo sortearlos. Mencionaré algunas de ellas: El recuerdo dosificador; el escondite; el paréntesis; la clandestinidad; la mirada privilegiada; la presencia ausente; la curiosidad; el vínculo grato con el exterior; la imaginación y la creatividad.

Espero que estas estrategias se puedan utilizar ahora, en el "día a día", porque estamos siendo expulsados de los espacios que habitamos. Como una de las reclusas comentaba: de mis pensamientos, mis deseos y de mi cuerpo nadie me podrá expulsar. La marginación propicia otras formas de estar y de ser en el mundo. Genera un constante diálogo interno, un habitar el cuerpo porque es lo único habitable de lo que no se le puede despojar, a menos que se le mate. El diálogo interno y corporal, propicia formas de acercamiento afectivo y creativo hacia sí mismo, así como la creación de refugios "citadinos" que propicien ambientes de confianza e intimidad, frente al peligro de despojo que representa el exterior.

\section{ESPACIOS DE REFUGIO}

Cortazar, bien nos plantea en el cuento de La Casa tomada, la pérdida de los espacios propios y la expulsión de los mismos. El despojo por quién sabe qué razón y, de todos modos, eso ya no importa cuando se queda sin nada. Desgracia o privilegio de no tener, de no pertenecer a ningún sitio, sólo a sí mismo.

Los primeros días nos pareció penoso porque ambos habíamos dejado en la parte tomada muchas cosas que queríamos [...] No está aquí [...] Y era una cosa más de todo lo que habíamos perdido al otro lado de la casa [...] Pero también tuvimos ventajas [...] Han tomado esta parte -dijo Irene. El tejido le colgaba de las manos y las hebras iban hasta la cancel y se perdían debajo. Cuando vio que los ovillos habían quedado del otro lado, soltó el tejido sin mirarlo. - ¿Tuviste tiempo de traer alguna cosa? -le pregunte inútilmen- 
te. No, nada. Estábamos con lo puesto [...] Antes de alejarnos tuve lástima, cerré bien la puerta de entrada y tiré la llave a la alcantarilla. No fuese que a algún pobre diablo se le ocurriera robar y se metiera en la casa, a esa hora y con la casa tomada.

Es indispensable la creación de espacios de refugio, ligados al enriquecimiento espiritual y artístico, ya no son suficientes las salidas esporádicas al cine, al teatro, al museo o a algún concierto. La creación de refugios creativos frecuentes y permanentes, como se realizan en los grupos marginados, son indispensables para tener un empoderamiento grupal y temporo-espacial; si es que llegara el momento de la expulsión total podríamos sobrevivir con mayor facilidad.

En la gran urbe, se vive ya sin sorpresa, la indiferencia es una forma de estar, una especie de obra en la que tanto los actores y el público no se inmutan, pueden pasar cosas terribles, pero se miran como algo cotidiano. La violencia es familiar y su multiplicidad de manifestaciones también. En esta puesta escénica, un tanto cruel, ya se ha perdido la capacidad de asombro y los encuentros resultan esporádicos, reina la desconfianza, la carencia de vínculos y la soledad. Cuerpos que agitados van con premura, que ya no miran a su alrededor, que no voltean a ver el cielo. Mucho menos a charlar con alguien desconocido, es un peligro, y si alguno se atreve lo miran como loco o sospechoso. Hacemos el papel de "hombrecillos insignificantes" y, cuando actuamos y cuando somos espectadores, simplemente tomamos la mayor distancia y nos volteamos como si nada pasara. La gran urbe es: el teatro de la indeferencia.

\section{LA MIRADA ESCÉNICA PSICODRAMÁTICA ANTE LA INDIFERENCIA}

La indiferencia y la mirada escénica psicodramática encuentran eco en el libro $E l$ sentido de la vista de Berger, del cual rescato algunos fragmentos.

Se da una indiferencia entre espectador y actor. Entre el público y los actores [...] La soledad suele confundirse con el triunfo de la indiferencia y se hace de ella algo enteramente negativo [...] La antítesis del teatro de la indiferencia, no es la simplicidad espontánea sino el drama en el que los protagonistas fundamentales y el público tienen un interés común [...] La condición histórica esencial del teatro de la indiferencia es que todos conscientemente, vanamente, dependen de las decisiones y opiniones de otros para la parte de las facetas de sus vidas. Para decirlo de forma simbólica, el teatro se ha construido sobre las ruinas del foro [...] En el teatro de la indeferencia, las apariencias ocultan el fracaso, las palabras ocultan los hechos y los símbolos ocultan sus referentes.

El escenario de la marginación en la cotidianeidad de la violencia en el que se transita rebasa la imaginación. El marginado habita y cohabita en la destrucción externa 
e interna. No se le escucha y, para él, ya no hay nada más qué hacer. Recuerdo las palabras de un preso de la Ciudad de México:

A veces, sólo me resta esperar, no sé a ciencia cierta qué espero, pero hay que esperar, posiblemente es la curiosidad la que me mantiene en ocasiones con un ánimo extraño; sí, la curiosidad [...] qué pasará conmigo, no lo sé, no depende de mí, eso me mantiene vivo y en ocasiones alerta, poder explorar en mi imaginación qué seguirá.

Marginación y destrucción, compañeras inseparables. Al leer el periódico día a día se confronta y comprueba esta atroz y vergonzante realidad.

El 28 de junio del 2010, Luis Valdez, dramaturgo y cineasta en su escrito para el periódico La Jornada, expresa: Ningún muro puede quebrar la conexión de los mexicanos con los E.E.U.U.

Yo agregaría: Ningún gobierno tiene por qué propiciar la ruptura de las relaciones humanas cálidas, ni aunque para ello sea necesaria una gran dosis de conciencia, inteligencia y creatividad, para que estas puedan sobrevivir en los actuales tiempos de marginación en sus múltiples formas. Y así como lo declara Ángel Vargas:

Hace cien años mis abuelos y bisabuelos cruzaron el desierto entre Sonora y Arizona para ir a pizcar algodón y trabajar en la minas de cobre en el vecino país, y posteriormente trasladarse a los viñedos de California, mi familia jamás perdió su identidad mexicana. Hemos sobrevivido - prosiguió- y tengo el orgullo y el privilegio de poder representar a los migrantes, a mi familia de carne y hueso, y probar que nada se perdió en un siglo. Y seguiré luchando desde la trinchera del arte.

En mi caso, desde la trinchera del psicodrama. 


\section{CONCLUSIONES}

Mi propuesta actual de investigación-intervención psicodramática es, propiciar momentos de encuentro grupal, en diversos espacios (laborales, educativos, y con grupos abiertos), mínimo de una a dos veces por mes, en los que se dramaticen las situaciones de marginación y vulnerabilidad cotidiana y las diversas respuestas para ello. En una primera etapa, que será de identificación frente a las formas citadinas de vivencias violentas y las estrategias que se han desarrollado para sortearlas y, en la segunda, donde el grupo, una vez constituido y con toda la confianza, proponga temas de trabajo grupal para continuar "sobreviviendo" en la gran urbe. En la tercera etapa, conformar grupos de apoyo, sistematizando las dos etapas anteriores y con personal capacitado para poder hacer propuestas en diversos espacios citadinos (instituciones, espacios públicos, diversas colonias) con el abanico psicodramático como teatro espontáneo, sociodrama, multiplicación dramática, etcétera. Éste es el inicio en la construcción de un proyecto titulado: La marginación cotidiana, espacio de invisibilidad. Mismo que buscará el apoyo universitario y los vínculos interinstitucionales pertinentes.

Hacer una ruptura con lo cotidiano, a partir de la creación de refugios que permitan otras formas de ser y estar en el mundo habitando ese "otro lugar", lugar de intimidad y despliegue creativo, aunque para ello sea indispensable la conciencia y la clandestinidad. 


\section{REFERENCIAS BIBLIOGRÁFICAS}

BERGER, J. (2000) El sentido de la vista. España, Alianza.

CORTAZÁR, J. (2008) Bestiario. Todos los fuegos el fuego, Alfaguara, México.

FOUCAULT, M. (1976) La vida de los hombres infames. Madrid, La Piqueta.

FOUCAULT, M. (2008) Los anormales. México, Fondo de Cultura Económica.

GOFFMAN, E. (1992) Estigma. Buenos Aires, Amorrortu.

MANERO, R. (2002) Anuario de Investigación. UAM-X. México.

MORENO, J. (1965) Psicodrama. Buenos Aires, Paidós.

MORENO, J. (1966) Pisicoterapia de grupo y Psicodrama. México, F.C.E 